\title{
Colorimetric determination of amaranth followed enrichment and separation using buoyant adsorbents
}

\author{
Shu Wu, Yuanyuan Yu, Cengceng Zhang and Fang Chen * (D)
}

\begin{abstract}
A buoyant solid-phase extraction adsorbent was prepared by sodium alginate-coated hollow glass microspheres (HGMs) modified with 3-aminopropyltrimethoxysilane (3-APTS) for the separation and enrichment of anionic dye amaranth. After adsorbing amaranth, these low-density adsorbents can float on the surface of the solution, so the separation between adsorbents and substrates can be carried out by flotation. Quantitative determination of amaranth after separation and enrichment can be achieved by combining spectrophotometry. Under the optimum conditions, the linear range and detection limit for amaranth detection were $0.02 \mathrm{mg} \mathrm{L}^{-1}-2.0 \mathrm{mg} \mathrm{L}^{-1}$ and $0.0021 \mathrm{mg}$ $\mathrm{L}^{-1}$, respectively. The proposed method was applied to the determination of amaranth in different beverages, and the results were in good agreement with those by high-performance liquid chromatography (HPLC). The recoveries of amaranth in different beverages were between 97.93 and 105.91\%. The floating adsorbent can be used as a conventional sample preparation method for the detection of low concentration analytes in complex samples.
\end{abstract}

Keywords: Dispersive solid-phase extraction, Amaranth, Hollow glass microspheres, Sample preparation, Determination

\section{Introduction}

Sample pretreatment is the main source of error in the analysis process. As the time-determining step in the entire sample analysis, it accounts for about two-thirds of the analysis time (Hyotylainen 2009). Traditional sample preparation methods mainly depend on solvent extraction, including liquid-liquid extraction (LLE) and Soxhlet extraction (Hyotylainen and Riekkola 2008). However, the extensive use of organic solvents would pollute the environment, and the complex process is time-consuming, resulting in low accuracy and low efficiency (Hyotylainen 2009; Boyaci et al. 2015). Furthermore, the trend of modern sample preparation technology is environmental friendliness, less sample volume, suitable for more complex sample matrices, and faster analysis. Novel sample preparation methods include dispersive solid phase extraction (d-SPE) (Cui et al. 2015), solid-phase micro-extraction (SPME) (Erica A. et al. 2015), micro-solid phase extraction ( $\mu$-SPE) (Basheer et al.

\footnotetext{
* Correspondence: fchen@mail.hust.edu.cn

Hubei Key Laboratory of Bioinorganic Chemistry and Materia Medica, Key Laboratory of Material Chemistry for Energy Conversion and Storage (HUST), Ministry of Education, School of Chemistry and Chemical Engineering, Huazhong University of Science and Technology, Wuhan 430074, China
}

2006), magnetic solid-phase extraction (MSPE) (Cai et al. 2016), and so on. Among them, d-SPE has received wide attention due to its many advantages, such as uncomplicated operation, high efficiency, and low dosage of organic solvents. In d-SPE, the adsorbent is dispersed in the sample solution, which can accelerate adsorption equilibrium and avoid blockage of the adsorption channel (Islas et al. 2017). In addition, d-SPE can be combined with a variety of analytical instruments, just like absorption spectra detection (Hu et al. 2012), mass spectrometry (MS) (Surma et al. 2014), high-performance liquid chromatography (HPLC) (Lankova et al. 2016), fluorescence (FL) (Hu et al. 2011), and so on. At present, dispersive solidphase extraction technology has been widely applied in food analysis (Yavuz et al. 2018; Bigdelifam et al. 2017).

As the key step in d-SPE, the choice of adsorbents must take into account their physical and chemical properties to maximize the interaction between the adsorbent and the analyte, and eliminate matrix interferences (Fagerquist et al. 2005). Secondly, the separation process also affects the accuracy of the analysis results. The current mechanical separation methods mainly include centrifugation and magnetic separation. These two methods are complicated 
and susceptible to solid impurities. There are many nanomaterials might be used as adsorbent carrier such as hollow $\mathrm{Cu}_{2} \mathrm{O}$ spheres (Luo et al. 2018), graphene "nets" (Liu et al. 2018), ceramic matrix composites (Tong et al. 2018), HGMs were selected due to its low-density, good liquidity, and readily available. Adsorbent and the matrix can be separated by flotation which is beneficial to analyze the trace substance in a real sample. Specific groups can be modified on the surface of HGMs according to the structure of the target analyte. In this way, not only the specificity of the substance can be recognized, but also the separation process can be simplified, and the sample loss can be reduced, then the accuracy of analysis can be improved.

Amaranth $\left(M=604.47 \mathrm{~g} \mathrm{~mol}^{-1}\right)$ is a common azo dye that has been widely used in textiles, pharmaceuticals, and food industries. Due to the structure containing a conjugated benzene ring structure and an azo structure, longterm intake can cause many problems which include tumor, allergy, and respiratory (Severo et al. 2016; Chandran et al. 2014). At present, there are a variety of methods for determining the content of amaranth in food and beverage products, for instance, spectrophotometry (Sha and Zhu 2015), liquid chromatography (Shen et al. 2014), thin layer chromatography (De Andrade et al. 2014), and electrochemical methods (Huang et al. 2017). However, it is still important to establish simple, highly selective, and environmentally friendly pretreatment methods for the analysis of amaranth in complex practical samples.

In this work, a buoyant solid-phase extraction adsorbent was prepared for the separation and enrichment detection of anionic dye amaranth. The adsorbent was fabricated by modification of 3-aminopropyltrimethoxysilane (3-APTS) on the surface of hollow glass microspheres (HGMs) by a dehydration reaction between hydroxyl groups, and coated with sodium alginate to prevent aggregation. Compared with other biomass templates for the synthesis of composite material, just like cellulose (Zhang et al. 2019a) and yeast (Zhao et al. 2018), sodium alginate contained a large number of carboxyl groups and had biocompatibility, biodegradability, and non-toxicity (Ma et al. 2019). The solid-phase extraction adsorbent ALG/3-APTS/HGMs (sodium alginate-coated HGMs modified with 3-APTS) can be used to enrich and separate anionic dye. In the acidic condition, the separation and enrichment of amaranth were realized by the electrostatic interaction between the anionic dye and the amino cation on the surface of the adsorbent. Combined with ultraviolet-visible (UV-vis) spectrophotometer, a method for determination of amaranth in beverages was established. The principle of synthesis and application is shown in Fig. 1.

\section{Experimental}

\section{Materials and instrument}

All chemicals were of analytical reagent grade. Hollow glass microspheres S38HS were purchased from $3 \mathrm{M}$
Company (USA). 3-aminopropyltrimethoxysilane was obtained from Shanghai Saen Chemical Technology Co., Ltd. (Shanghai, China). Sodium hydroxide $(\mathrm{NaOH})$, ammonia, ethanol, calcium chloride $\left(\mathrm{CaCl}_{2}\right)$, sulfuric acid $\left(\mathrm{H}_{2} \mathrm{SO}_{4}, 98 \%\right)$, hydrochloric acid $(\mathrm{HCl})$, amaranth, and sodium alginate were purchased from Sinopharm Chemical Reagent Co., Ltd. (Shanghai, China). Deionized water was used throughout.

Fourier transform infrared (FTIR) spectra were obtained by an infrared spectrometer (EQUINOX 55, BRUKER), and the test range of $400 \mathrm{~cm}^{-1}$ to $4000 \mathrm{~cm}^{-1}$. UV-vis absorption spectra were measured with the wavelength range of $300-700 \mathrm{~nm}$ on an UV2600 spectrophotometer (Shimadzu). The morphology of the composite materials was investigated by field emission scanning electron microscope (FESEM) (Hitachi-SU8010, Japan). Precision booster electric stir bar (JJ-1, Jintan Youlian Instrument Research Institute), collector type constant temperature heating magnetic stirrer (DF-101S, Zhengzhou Brocade Instrument Co., Ltd.) and digital water bath thermostatic reciprocating shaker (Jintan Kexing Instrument Factory) were used for separation of amaranth. Vacuum drying oven (DZF-6030A, Shanghai Heng Technology Co., Ltd.) and electronic balance (BS124S, BSISL) were used for the preparation of the adsorbent. Acidity was detected by pHS-3C Thunder Magnetic Acidity Meter (Shanghai Precision Scientific Instrument Co., Ltd.).

\section{Preparation of ALG/3-APTS/HGMs}

HGMs and $\mathrm{NaOH}\left(1 \mathrm{~mol} \mathrm{~L}^{-1}\right)$ solution were mixed and slowly mechanically stirred for $6 \mathrm{~h}$. After deposition of 24 $\mathrm{h}$, the mixture was filtered under reduced pressure and rinsed with distilled water until the $\mathrm{pH}$ of the filtrate was around 7 , and then dried under vacuum for $24 \mathrm{~h}$. The dry powder products were dispersed in the mixture of absolute ethanol and double distilled water ( $\mathrm{v} / \mathrm{v}=9: 1)$ and ammonia in a three-necked round bottom flask and sonicated for $5 \mathrm{~min}$. After that, the silane coupling agent 3-APTS was dispersed into the mixture and sonicated for $30 \mathrm{~min}$, followed by mechanically stirred for $6 \mathrm{~h}$ at $60^{\circ} \mathrm{C}$ and stand overnight. After separated by flotation, the supernatant was collected and vacuum filtered under reduced pressure. The products were vacuum dried for $48 \mathrm{~h}$ to prepare 3-APTS/HGMs.

Three grams of 3-APTS/HGMs was dissolved in $1.0 \mathrm{~g}$ of sodium alginate solution (2\%) with mechanically stirred for $3 \mathrm{~h}$, and sonicated for $5 \mathrm{~min}$ to form a homogeneous slurry mixture. Then the mixture was carefully dropped into a $\mathrm{CaCl}_{2}$ solution $\left(0.1 \mathrm{~mol} \mathrm{~L}^{-1}\right)$ by syringe to obtain ALG/3-APTS/HGMs. Finally, the products were transferred to $\mathrm{CaCl}_{2}$ solution and magnetically stirred for $12 \mathrm{~h}$, then washed with distilled water and dried at $60{ }^{\circ} \mathrm{C}$ for $12 \mathrm{~h}$. 


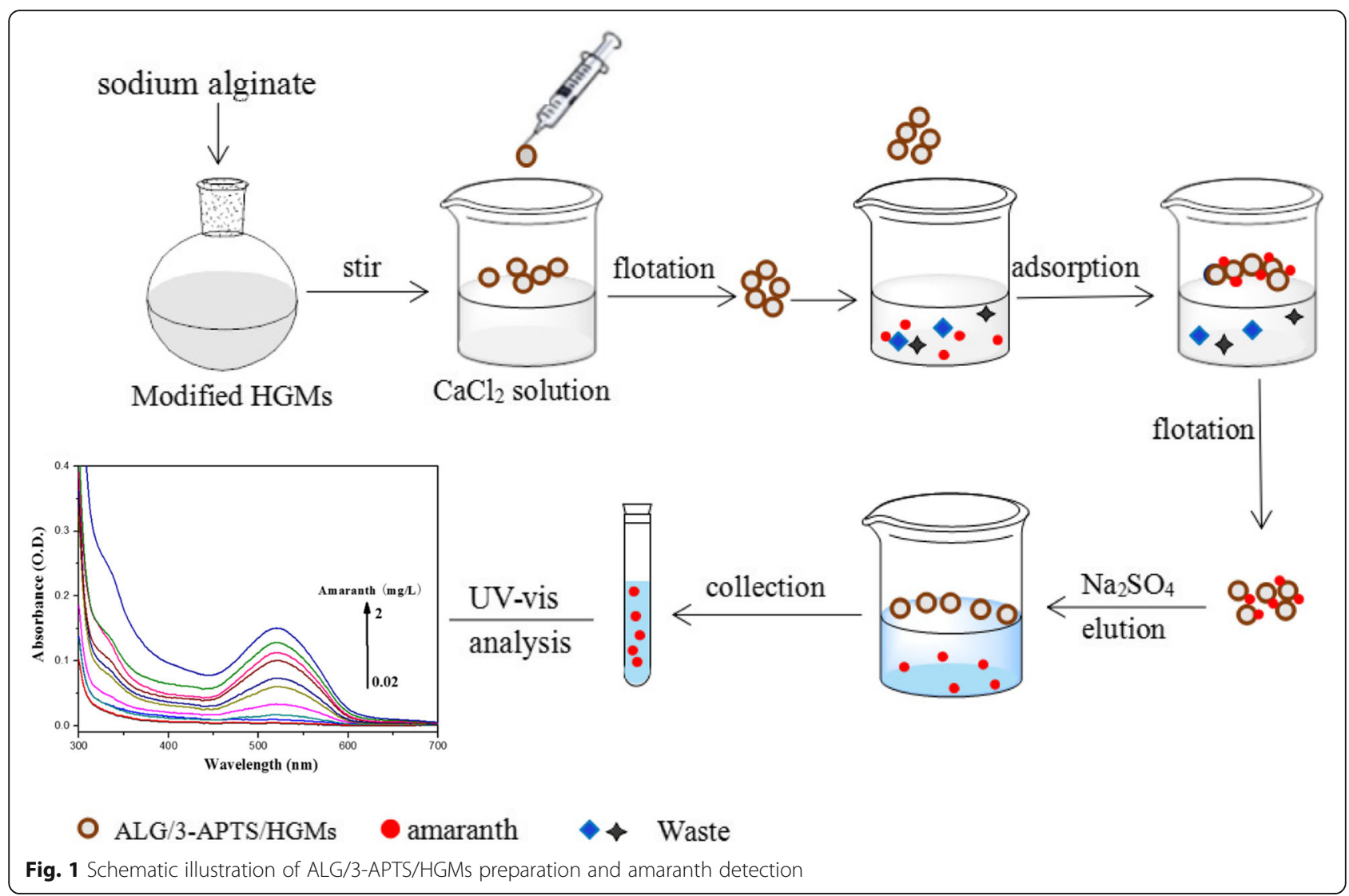

\section{Adsorption experiment}

The investigation of amaranth adsorption was conducted in a batch experiment, and the influences of different parameters, such as adsorbent dosage, time, $\mathrm{pH}$, temperature, and solution volume were studied. Typically, $0.24 \mathrm{~g}$ of ALG/3-APTS/HGMs was dispersed in a certain concentration of amaranth solution and was shaken for 7 $\mathrm{h}$ at $30^{\circ} \mathrm{C}$ on a digital water bath thermostatic reciprocating shaker at $200 \mathrm{rpm}$ until equilibrium was reached. After standing, the adsorbents collected by flotation were desorbed and filtered. The concentration of amaranth was analyzed by absorption at $522 \mathrm{~nm}$. The enrichment factor (EF) of ALG/3-APTS/HGMs was calculated on the basis of the following equations (Tang et al. 2014).

$$
\mathrm{EF}=\frac{C a}{C 0}
$$

Where $C_{O}\left(\mathrm{mg} \mathrm{L}^{-1}\right)$ is the initial concentration of amaranth and $\mathrm{Ca}\left(\mathrm{mg} \mathrm{L}^{-1}\right)$ is the enriched concentration of amaranth.

\section{Desorption experiment}

Under the optimal adsorption conditions, the desorbent dosage, concentration, temperature, and time were optimized. After adsorption, saturated load adsorbents and $5 \mathrm{~mL}$ of sodium sulfate $\left(\mathrm{Na}_{2} \mathrm{SO}_{4}, 6 \mathrm{~mol} \mathrm{~L}^{-1}\right)$ were vortex mixed for $8 \mathrm{~h}$ at $20^{\circ} \mathrm{C}$, and then filtered through a $0.45 \mu \mathrm{m}$ filter. The other procedures were consistent with the adsorption experiments.

\section{Pretreatment of real sample}

Beverages were purchased from a supermarket. Ten milliliters of the soda beverage was sonicated for $40 \mathrm{~min}$ to remove $\mathrm{CO}_{2}$. Then, it was filtered using a $0.22 \mu \mathrm{m}$ filter and added with distilled water to $100 \mathrm{~mL}$.

One hundred milliliters of a brand premixed beverage was heated in $80^{\circ} \mathrm{C}$ water for $30 \mathrm{~min}$ to remove the ethanol from the sample and filtered through a $0.22 \mu \mathrm{m}$ filter. Both of them were stored in a refrigerator.

\section{Results and discussion}

\section{Characterization of ALG/3-APTS/HGMs}

Figure 2 shows the scanning electron microscope (SEM) images of HGMs and ALG/3-APTS/HGMs and photographs of before and after the adsorption. As shown in Fig. 2a, untreated HGMs were spherical particles with good dispersion and smooth surface, and their diameters were in the range of $10-20 \mu \mathrm{m}$. It could be observed 


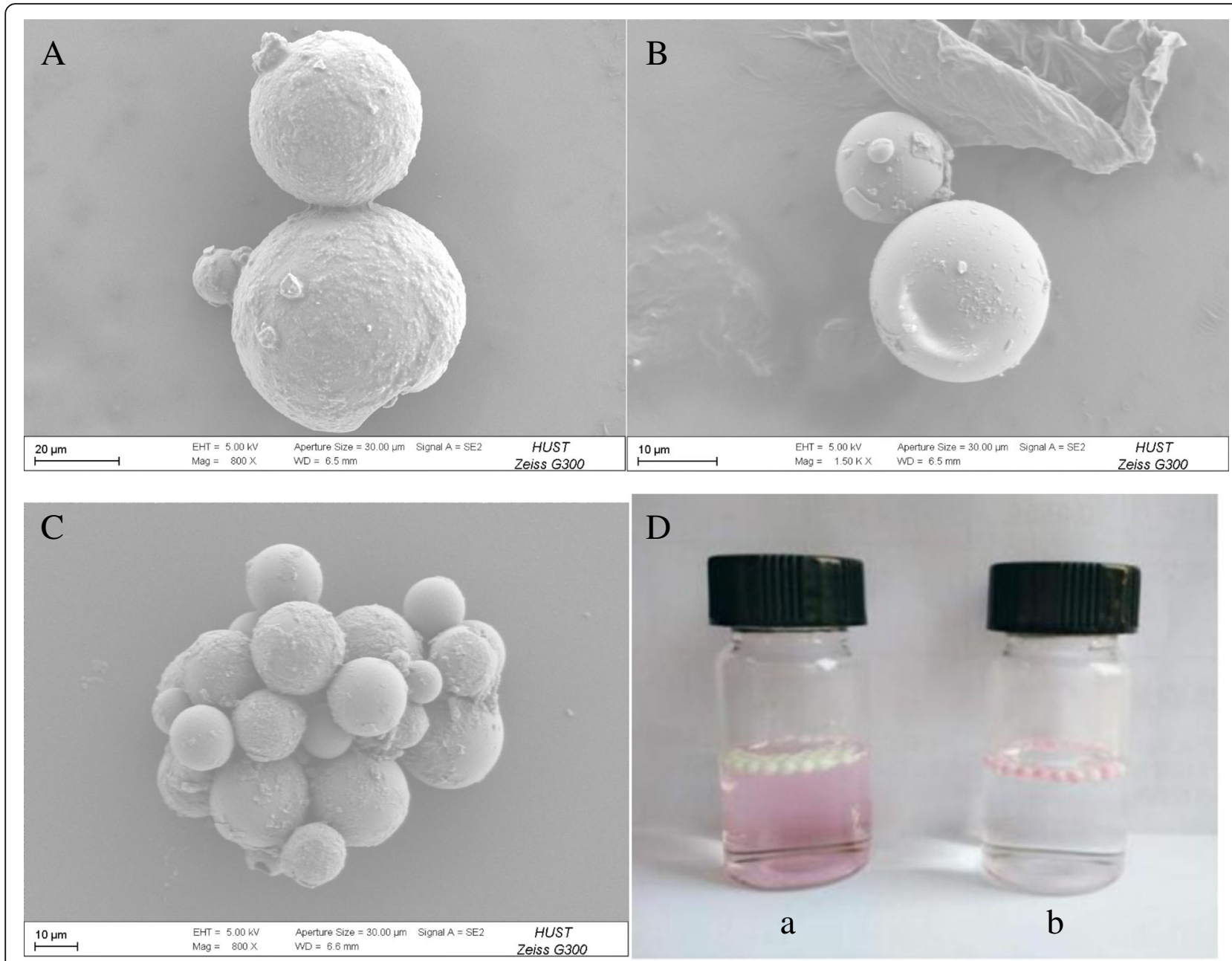

Fig. 2 SEM images of untreated HGMs (A), ALG/3-APTS/HGMs (B, C). D Comparative photos of ALG/3-APTS/HGMs before (a) and after (b) amaranth adsorption

from Fig. 2b and Fig. 2c that the surface of ALG/3APTS/HGMs was coarser and had more small bulges than that of untreated HGMs, indicating that the organic film was coated on the surface of the HGMs. The FT-IR spectra also indicated that the HGMs had been successfully modified by silane coupling agent 3-APTS, which was consistent with the results of the SEM images (Additional file 1: Figure S1).

The results of anionic dye adsorption using the ALG/3-APTS/HGMs indicated that the adsorbent had a strong adsorption capacity for amaranth. Figure $2 \mathrm{~d}$ is a photograph of before and after the adsorption of amaranth in aqueous solution. The pink solution became transparent after the adsorption. It proved that there was an interaction between amaranth and ALG/3-APTS/HGMs that could use for separation and enrichment of amaranth. The negatively charged amaranth could be captured by electrostatic attraction with the positively charged amino group on the adsorbent.

\section{Effect of $\mathrm{pH}$}

The $\mathrm{pH}$ value plays a vital role in adsorption as the surface charge of the adsorbents is dependent on $\mathrm{pH}$. The relationship between adsorption capacity and $\mathrm{pH}$ adjusted with $\mathrm{HCl}$ or $\mathrm{NaOH}$ in the range of $1-10$ is presented in Fig. 3a. The maximum adsorption capacity of amaranth on the ALG/3-APTS/HGMs occurred at pH 1.0. The adsorption efficiency decreased rapidly with increasing $\mathrm{pH}$. Under the strongly acidic conditions, the protonation of the amino group on the adsorbent was the largest, which could efficiently capture the negatively charged amaranth by electrostatic attraction. With the increase of $\mathrm{pH}$, the protonation of the amino group decreased, which would 

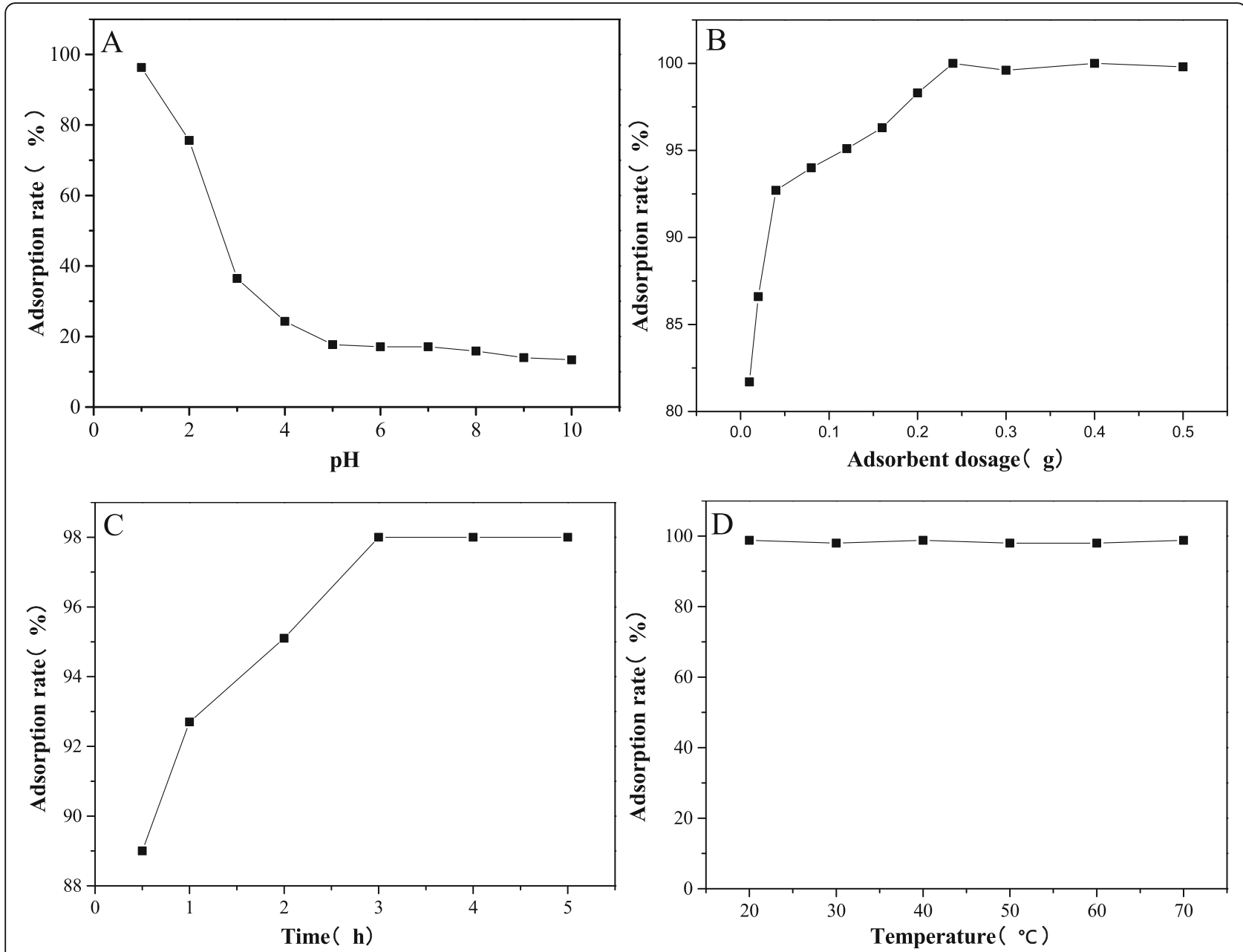

Fig. 3 Effect of pH (a), adsorbent dosage (b), time (c), and temperature (d) on the amaranth adsorption. (amaranth $2 \mathrm{mg} \mathrm{L}^{-1}$, oscillation speed 200 rpm)

in turn inhibit the amaranth adsorption. Thus, the optimum extraction $\mathrm{pH}$ was 1.0.

\section{Effect of adsorbent dosage}

The effect of adsorbent dosage on the adsorption rate was investigated, and the results of the experiment are presented in Fig. 3b. The adsorption percentage of $2 \mathrm{mg} \mathrm{L}^{-1}$ amaranth increased as the adsorbent dosage (0.01 g-0.24 g) increased and reached equilibrium while the amount of ALG/3-APTS/HGMs was $0.24 \mathrm{~g}$. Therefore, $0.24 \mathrm{~g}$ of ALG-APTS/HGMs was selected as the optimum amount.

\section{Effect of time}

Figure 3c shows the effect of adsorption time on enrichment efficiency. It could be seen that the adsorption rate reached a maximum value at $3 \mathrm{~h}$ and kept almost constant after $3 \mathrm{~h}$ as the adsorption was saturated. To gain the most satisfactory result, the optimum adsorption time was $3 \mathrm{~h}$.

\section{Effect of temperature}

The adsorption efficiency carried out at different temperatures was studied. As shown in Fig. 3d, no significant differences were observed in the range of $20-70{ }^{\circ} \mathrm{C}$, which indicated that the adsorption process was less affected by temperature. In order to simplify the operation process and save energy, $20^{\circ} \mathrm{C}$ (around room temperature) was chosen as the best temperature for the following study.

\section{Effect of solution volume}

The effect of the solution volume on adsorption efficiency was also investigated (Additional file 1: Table S1). The volume of amaranth solution had no obvious influence on results within $10-50 \mathrm{~mL}$, and the experimental value of EF was almost consistent with the theoretical value. However, the recovery rate reduced because of insufficient adsorption while volume was more than 50 $\mathrm{mL}$. Since the enrichment factor depends on the solution volume, a high solution volume provides a high enrichment factor. Too large a sample volume, however, 
could affect the adsorption of the amaranth onto the adsorbent, which would affect adsorption efficiency (Klongklaew et al. 2020). Therefore, in order to facilitate the operation, the volume of the amaranth solution was selected to be $10 \mathrm{~mL}$.

\section{Desorption experiment optimization Selection of desorbent}

To improve the desorption efficiency, desorption experiments were performed using different desorbents. The amaranth could be separated from ALG/3-APTS/ HGMs by the stronger electrostatic attraction with desorbents. As shown in Fig. 4a, amaranth could be desorbed via $\mathrm{HCl}, \mathrm{H}_{2} \mathrm{SO}_{4}, \mathrm{Na}_{2} \mathrm{SO}_{4}$, and $\mathrm{NaOH}$. The desorption rate (expressed by absorbance) of $\mathrm{H}_{2} \mathrm{O}$ was almost 0 , and $\mathrm{NaOH}$ was the best one. However, the physical form of ALG/3-APTS/HGMs damaged in high alkalinity conditions. Taking into account economic and environmental factors, $\mathrm{Na}_{2} \mathrm{SO}_{4}$ was chosen for desorption experiments.

\section{Effect of desorbent concentration}

Desorbent concentration was an important parameter in desorption. Figure 4b shows the dependence against the concentration of $\mathrm{Na}_{2} \mathrm{SO}_{4}$ for $0.24 \mathrm{~g}$ saturated adsorbent. As can be seen in Fig. 4b, the absorbance of amaranth separated from adsorbent became higher when increasing desorbent concentration up to $6 \mathrm{~mol}$ $\mathrm{L}^{-1}$ and then kept stable. Therefore, the best desorption rate was obtained under the standard conditions using a concentration of $6 \mathrm{~mol} \mathrm{~L}^{-1}$.

\section{Effect of time}

The effect of desorption time on desorption efficiency was studied. As presented in Fig. 4c, there was a clear dependence of desorption time and the elected amaranth
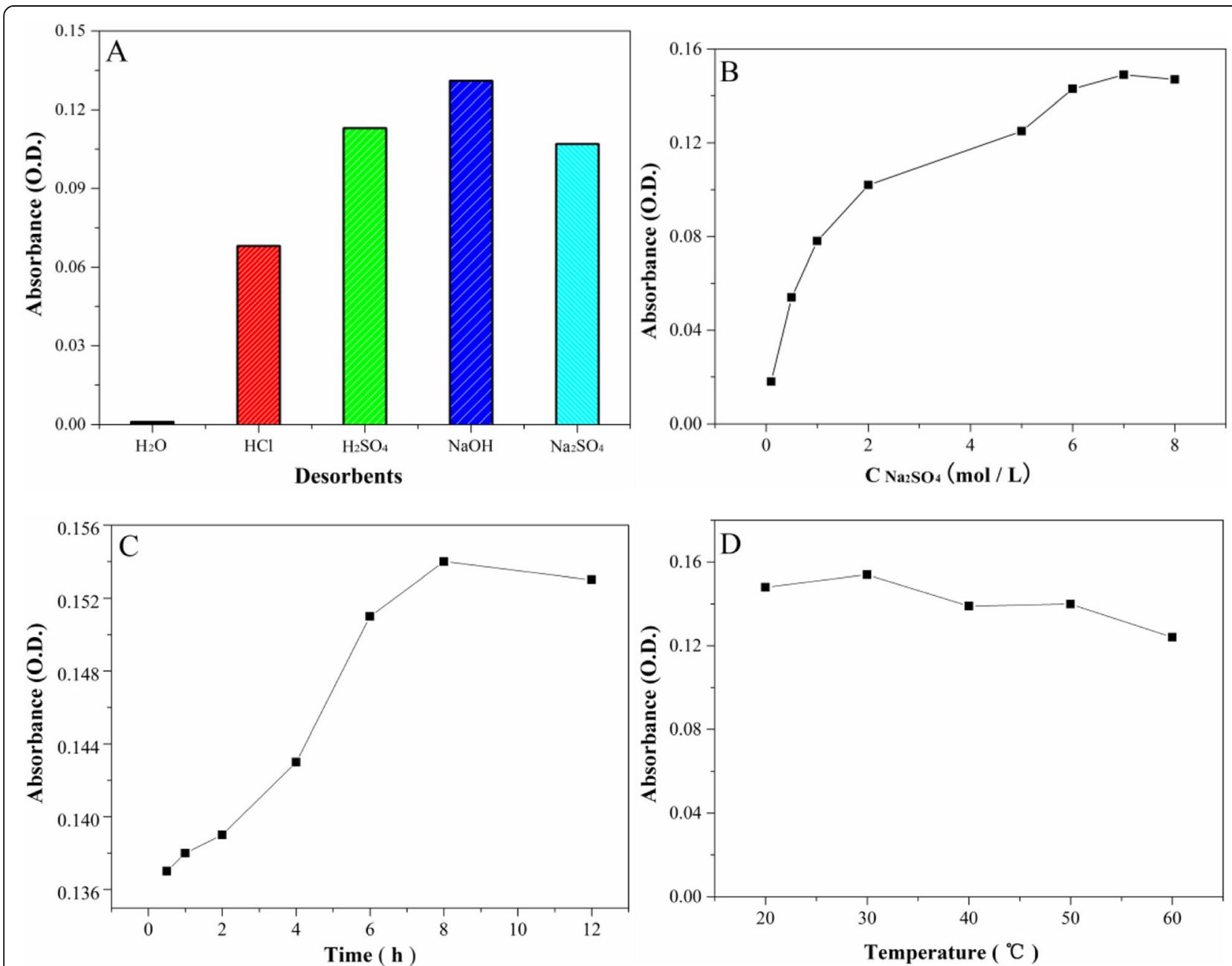

Fig. 4 Effect of desorbent (a), desorbent concentration (b), time (c), and temperature (d) on the amaranth desorption. (pH 1, adsorbent dosage $0.24 \mathrm{~g}$, adsorbent time $3 \mathrm{~h}$, adsorbent temperature $20^{\circ} \mathrm{C}$, amaranth $2 \mathrm{mg} \mathrm{L}^{-1}$, adsorption volume $10 \mathrm{~mL}$, oscillation speed 200 rpm, desorption volume $5 \mathrm{~mL}$ ) 


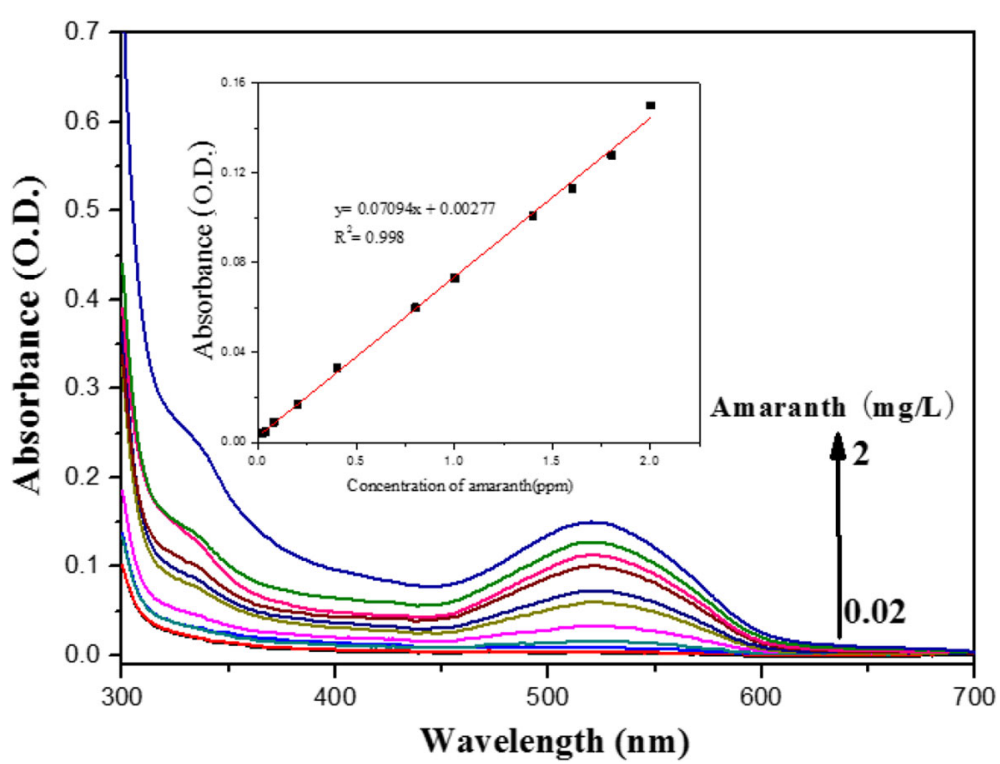

Fig. 5 UV-vis absorption spectra of the desorption solution of different concentrations of amaranth solution (inset: standard curve of concentration and absorbance)

absorbance, and it could be obviously observed that the absorbance reached a maximum value for $8 \mathrm{~h}$ of desorption.

\section{Effect of temperature}

The effect of temperature on desorption was investigated. The results (Fig. 4d) show that the desorption efficiency was higher in the range of $20-30^{\circ} \mathrm{C}$ than in the range of $30-60^{\circ} \mathrm{C}$. As a conclusion, the greater desorption rate was obtained at $20^{\circ} \mathrm{C}$.

\section{Method establishment and evaluation}

To verify the feasibility, the linearity and detection limit of this measurement were evaluated by varying the concentration of amaranth $(10 \mathrm{~mL})$ under optimum conditions discussed above. The absorbance of elected amaranth increased proportionately with amaranth added. The UVvis absorption spectra are shown in Fig. 5. The inset is a standard curve. It can be seen that a good linear relationship between absorbance and the concentration of amaranth was obtained in the range of $0.02 \mathrm{mg} \mathrm{L}^{-1}$ to $2 \mathrm{mg}$ $\mathrm{L}^{-1}$. The equation was $A=0.07094 c+0.00277$ ( $c$ : ppm, $\left.R^{2}=0.9998\right)$. The detection limit was calculated to be $0.0021 \mathrm{mg} \mathrm{L}^{-1}$, and the relative standard deviation (R.S.D.) was $2.2 \%$ for the determination of $2 \mathrm{mg} \mathrm{L}^{-1}$ amaranth. Compared with other conventional methods for detecting anionic dyes (Table 1), this method has a lower detection limit $(S / N=3)$, simpler operation, and lower cost. The detection limit was better than (Sha and Zhu 2015; De Andrade et al. 2014) or comparable with detection limit from some other works.

\section{Amaranth determination for real sample}

To investigate the validity of the proposed method, treated soda and premixed beverage were diluted to 100 and 10 times respectively with distilled water. The adsorption properties of ALG/3-APTS/HGMs were

Table 1 Comparison of detection methods of amaranth

\begin{tabular}{lllll}
\hline Methods & Pretreatment & Sample & LOD $(\mu \mathrm{g} / \mathrm{L})$ & ref \\
\hline UV-vis & LLE & Beverage, candy & 10 & Sha and Zhu 2015 \\
TLC-HPLC-PDA & SPE & Soft drink & 40 & De Andrade et al. 2014 \\
HPLC & MSPE & Drinks, cocktails, candy, etc. & 6.4 & Wu et al. 2016 \\
LC-ESI-MS/MS & SPE, LLE & Ice cream, chocolate candy & 5.0 & Martin et al. 2016 \\
icELISA & - & Beverage & 3.35 & Zhang et al. 2014 \\
MIP-electrochemical sensor & - & Soft drink & 1.21 & Li et al. 2019 \\
UV-vis & UA-D- $\mu$-SPE & Food and water samples & 3.83 & Noormohamadi et al. 2019 \\
Voltammetry & - & Jelly, water, fruit cakes, etc. & 1.27 & Tvorynska et al. 2019 \\
UV-vis & DSPE & Beverage & 2.1 & This work \\
\hline
\end{tabular}


Table 2 Results of amaranth detection by proposed method and HPLC

\begin{tabular}{lclcl}
\hline Sample & \multicolumn{2}{l}{ This work } & & HPLC \\
\cline { 2 - 3 } & Amaranth $(\mathrm{mg} / \mathrm{L})$ & RSD $(\%, n=5)$ & Amaranth $(\mathrm{mg} / \mathrm{L})$ & RSD $(\%, n=3)$ \\
\hline Soda beverage & 4.274 & 2.238 & 4.458 & 0.4133 \\
Premixed beverage & 0.348 & 1.410 & 0.325 & 1.441 \\
\hline
\end{tabular}

examined by absorption at $522 \mathrm{~nm}(n=5)$. Simultaneously, the Chinese standard detection method of amaranth in 2016 (HPLC) was also used to determine the content of amaranth in beverages (GB 5009.35-2016), and the two methods were compared in Table 2. It can be seen that the amount of amaranth measured by this method was in good agreement with the standard method (HPLC) and lower than the allowable limit of the national standard for amaranth in beverages $(\leqq 0.05$ $\mathrm{g} \mathrm{kg}^{-1}$ ) (GB2760-2014). The RSD was smaller than 3\% $(n=5)$. Therefore, the proposed method with great accuracy is feasible for amaranth detection in beverages.

To evaluate the matrix effect, a series of spiked recovery experiments were performed. The detail data are listed in Table 3. As can be seen clearly, the recoveries for detection were between 90 and $110 \%$, and the relative standard deviations were below $3 \%(n=6)$.

\section{Conclusions}

A buoyant solid-phase extraction adsorbent was prepared by sodium alginate coated hollow glass microspheres (HGMs) modified with 3-aminopropyltrimethoxysilane (3-APTS). The adsorbent can adsorb amaranth and be separated by flotation because of low-density HGMs. This method could be used as a sample pretreatment method for the detection of amaranth in beverages and the results were in good agreement with those by HPLC. As a very promising material, HGMs can be modified with different silane coupling agents to adsorb and enrich corresponding pollutants. It is of great significance for the detection of contaminants whose concentration is below the detection limits of common analytical instruments. Furthermore, this kind of composite may realize the negative permittivity behavior by doping (Sun et al. 2019), and be functionalized for other applications, including metal-free energy storage systems (Zhang et al. 2019b) and photodegradation (Song et al. 2020).

Table 3 Results of the spiked recovery experiment

\begin{tabular}{lclll}
\hline Sample & $\begin{array}{l}\text { Amaranth } \\
\text { Labeled } \\
(\mathrm{mg} / \mathrm{L})\end{array}$ & $\begin{array}{l}\text { Amaranth } \\
\text { added } \\
(\mathrm{mg} / \mathrm{L})\end{array}$ & $\begin{array}{l}\text { Amaranth } \\
\text { detected } \\
(\mathrm{mg} / \mathrm{L})\end{array}$ & $\begin{array}{l}\text { Recovery } \\
(\%)\end{array}$ \\
\hline Soda beverage & 0.0427 & 0.5 & 0.572 & 105.91 \\
Premixed beverage & 0.174 & 0.5 & 0.664 & 97.93 \\
& & 1.0 & 1.031 & 98.85 \\
& & 1.0 & 1.165 & 99.07 \\
\hline
\end{tabular}

\section{Supplementary information}

Supplementary information accompanies this paper at https://doi.org/10. 1186/s40543-020-0204-2.

Additional file 1: Figure S1. FTIR spectra of HGMs (a), APTS (b), 3-APTSHGMs (c). Table S1. Effect of solution volume on adsorption efficiency of amaranth.

\section{Abbreviations}

3-APTS: 3-Aminopropyltrimethoxysilane; ALG/3-APTS/HGMs: Sodium alginatecoated HGMs modified with 3-APTS; d-SPE: Dispersive solid-phase extraction; EF: Enrichment factor; FESEM: Field emission scanning electron microscope;

FL: Fluorescence; FT-IR: Fourier-transform infrared spectroscopy;

HGMs: Hollow glass microspheres; HPLC: High-performance liquid chromatography; LLE: Liquid-liquid extraction; MS: Mass spectrometry; MSPE: Magnetic solid phase extraction; R.S.D.: Relative standard deviation; SEM: Scanning electron microscope; SPME: Solid-phase micro-extraction; UVvis: Ultraviolet-visible; $\mu$-SPE: Micro-solid phase extraction

\section{Acknowledgements}

This work was financially supported by the Fundamental Research Funds for the Central Universities (no. 2019kfyXKJC056) and the Program for HUST Academic Frontier Youth Team (no. 2018QYTD12).

\section{Authors' contributions}

This study was designed by FC. The experimental work was performed by SW and YY. SW and CZ drafted the manuscript and interpreted the data. All authors read and approved the final manuscript.

\section{Funding}

Fundamental Research Funds for the Central Universities (no. 2019kfyXKJC056).

Program for HUST Academic Frontier Youth Team (no. 2018QYTD12).

\section{Availability of data and materials}

Data sharing is not applicable in this article as no datasets were generated or analyzed during the current study.

\section{Competing interests}

The authors declare that they have no competing interests.

Received: 12 October 2019 Accepted: 29 January 2020 .

\section{References}

Basheer C, Alnedhary AA, Rao BSM, Valliyaveettil S, Lee HK. Development and application of porous membrane-protected carbon nanotube micro-solidphase extraction combined with gas chromatography/mass spectrometry. Anal Chem. 2006;78(8):2853-8.

Bigdelifam D, Hashemi M, Zohrabi P, Sadeghpour M, Radaee E. Sensitive magnetic dispersive solid-phase extraction using hydrophobic magnetic nanoparticles and GC-MS analysis for the determination of sterol composition in milk samples for the detection of palm oil. Anal Methods. 2017:9(14):2211-9.

Boyaci E, Rodriguez-Lafuente A, Gorynski K, Mirnaghi F, Erica A, Silva S, Hein D, Pawliszyn J. Sample preparation with solid phase microextraction and exhaustive extraction approaches: comparison for challenging cases. Anal Chim Acta. 2015;873:14-30.

Cai Y, Yan Z, Wang L, Van MN, Cai Q. Magnetic solid phase extraction and static headspace gas chromatography-mass spectrometry method for the analysis of polycyclic aromatic hydrocarbons. J Chromatogr A. 2016;1429:97-106. 
Chandran S, Lonappan LA, Thomas D, Jos T, Kumar KG. Development of an electrochemical sensor for the determination of amaranth: a synthetic dye in soft drinks. Food Anal Methods. 2014;7(4):741-6.

Cui X, Zhang P, Yang X, Yang M, Zhou W, Zhang S, Gao H, Lu R. B-CD/ATP composite materials for use in dispersive solid-phase extraction to measure (fluoro) quinolone antibiotics in honey samples. Anal Chim Acta. 2015:878:131-9.

De Andrade FI, Florindo Guedes MI, Pinto Vieira IG, Pereira Mendes FN, Salmito Rodrigues PA, Costa Maia CS, Marques Avila MM, Ribeiro LM. Determination of synthetic food dyes in commercial soft drinks by TLC and ion-pair HPLC. Food Chem. 2014;157(1):193-8.

Erica A. S-S, Reyes-Garces N, Gomez-Rios GA, Boyaci E, Bojko B, Pawliszyn J. A critical review of the state of the art of solid-phase microextraction of complex matrices III. Bioanalytical and clinical applications. Trac-Trend Anal Chem. 2015;71(1):249-64.

Fagerquist CK, Lightfield AR, Lehotay SJ. Confirmatory and quantitative analysis of $\beta$-lactam antibiotics in bovine kidney tissue by dispersive solid-phase extraction and liquid chromatography-tandem mass spectrometry. Anal Chem. 2005;77(5):1473-82

GB 5009.35-2016, Determination of synthetic colorants in national food safety standards, 2016.

GB2760-2014, National standards for food safety standards for the use of food additives, 2014

Hu XZ, Chen ML, Gao Q, Yu QW, Feng YQ. Determination of benzimidazole residues in animal tissue samples by combination of magnetic solid-phase extraction with capillary zone electrophoresis. Talanta. 2012;89(2):335-41.

Hu Y, Li Y, Liu R, Tan W, Li G. Magnetic molecularly imprinted polymer beads prepared by microwave heating for selective enrichment of $\beta$-agonists in pork and pig liver samples. Talanta. 2011;84(2):462-70.

Huang W, Zhang M, Hu W. N-methyl-2-pyrrolidone-exfoliated graphene nanosheets as sensitive determination platform for amaranth at the nanomolar level. Ionics. 2017;23(1):241-6.

Hyotylainen T. Critical evaluation of sample pretreatment techniques. Anal Bioanal Chem. 2009:394(3):743-58.

Hyotylainen T, Riekkola ML. Sorbent and liquid-phase microextraction techniques and membrane-assisted extraction in combination with gas chromatographic analysis: a review. Anal Chim Acta. 2008;614(1):27-37.

Islas G, Ibarra IS, Hernandez P, Miranda JM, Cepeda A. Dispersive solid phase extraction for the analysis of veterinary drugs applied to food samples: a review. Int J Anal Chem. 2017:2017:1-16.

Klongklaew P, Kanatharana P, Bunkoed O. Development of doubly porous composite adsorbent for the extraction of fluoroquinolones from food samples. Food Chem. 2020;309:125685.

Lankova D, Urbancova K, Sram RJ, Hajslova J, Pulkrabova J. A novel strategy for the determination of polycyclic aromatic hydrocarbon monohydroxylated metabolites in urine using ultra-high-performance liquid chromatography with tandem mass spectrometry. Anal Bioanal Chem. 2016;408(10):2515-25.

Li L, Zheng H, Guo L, Qu L, Yu L. A sensitive and selective molecularly imprinted electrochemical sensor based on Pd-cu bimetallic alloy functionalized graphene for detection of amaranth in soft drink. Talanta. 2019;197:68-76.

Liu MK, Meng QH, Yang ZY, Zhao XS, Liu TX. Ultra-long-term cycling stability of an integrated carbon-sulfur membrane with dual shuttle-inhibiting layers of graphene "nets" and a porous carbon skin. Chem Commun. 2018;54(40):5090-3.

Luo XL, Pan Z, Pei F, Jin ZP, Miao KK, Yang PF, Qian HM, Chen Q, Feng GD. In situ growth of hollow $\mathrm{Cu}_{2} \mathrm{O}$ spheres using anionic vesicles as soft templates. J Ind Eng Chem. 2018;59:410-5.

Ma RX, Wang YJ, Qi HJ, Shi C, Wei GB, Xiao LD, Huang ZH, Liu SX, Yu HP, Teng CB, Li $H$, Murugadoss V, Zhang JX, Wang YG, Guo ZH. Nanocomposite sponges of sodium alginate/graphene oxide/polyvinyl alcohol as potential wound dressing: in vitro and in vivo evaluation. Compos Part B. 2019;167:396-405.

Martin F, Oberson JM, Meschiari M, Munari C. Determination of 18 water-soluble artificial dyes by LC-MS in selected matrices. Food Chem. 2016;197:1249-55.

Noormohamadi HR, Fathi MR, Ghaedi M, Nobakht V, Azizzadeh S. DNA-shaped silver(I) coordination polymer based micro-solid phase extraction for determination of amaranth and brilliant blue FCF in food and water samples. Anal Methods. 2019;11:618-26.

Severo ED, Anchieta CG, Foletto VS, Kuhn RC, Collazzo GC, Mazutti MA, Foletto EL. Degradation of amaranth azo dye in water by heterogeneous photoFenton process using $\mathrm{FeWO}_{4}$ catalyst prepared by microwave irradiation. Water Sci Technol. 2016;73(1):88-94.

Sha O, Zhu X. Simultaneous ionic liquid aqueous two-phase extraction and spectrophotometric determination of amaranth and brilliant blue in food samples. J Anal Chem. 2015;70(5):558-65.
Shen $Y$, Zhang X, Prinyawiwatkul W, Xu Z. Simultaneous determination of red and yellow artificial food colourants and carotenoid pigments in food products. Food Chem. 2014;157(8):553-8.

Song B, Wang Q, Wang L, Lin J, Wei X, Murugadoss V, Wu SD, Guo ZH, Ding T, Wei SY. Carbon nitride nanoplatelet photocatalysts heterostructured with Bdoped carbon nanodots for enhanced photodegradation of organic pollutants. J Colloid Interface Sci. 2020;559:124-33.

Sun K, Dong JN, Wang ZX, Wang ZY, Fan GH, Hou Q, An LQ, Dong MY, Fan RH, Guo ZH. Tunable negative permittivity in flexible graphene/PDMS metacomposites. J Phys Chem C. 2019;123(38):23635-42.

Surma M, Sadowska-Rociek A, Cieslik E. The application of d-SPE in the QuEChERS method for the determination of PAHs in food of animal origin with GC-MS detection. Eur Food Res Techenol. 2014;238(6):1029-36.

Tang S, Chia GH, Chang Y, Lee HK. Automated dispersive solid-phase extraction using dissolvable $\mathrm{Fe}_{3} \mathrm{O}_{4}$-layered double hydroxide core-shell microspheres as sorbent. Anal Chem. 2014;86:11070-6.

Tong YG, Cai ZH, Bai SX, Hu YL, Hua MY, Xie W, Ye YC, Li Y. Microstructures and properties of Si-Zr alloy based CMCs reinforced by various porous C/C performs. Ceram Int. 2018:44(14):16577-82.

Tvorynska S, Josypcuk B, Barek J, Dubenska L. Electrochemical behavior and sensitive methods of the voltammetric determination of food azo dyes amaranth and allura red AC on amalgam electrodes. Food Anal Methods. 2019;12:409-21.

Wu H, Gao N, Zhang L, Li Y, Shi Y, Du L. Automated magnetic solid-phase extraction for synthetic food colorant determination. Food Anal Methods. 2016;9(3):614-23.

Yavuz E, Tokalioglu S, Pata S. Core-shell $\mathrm{Fe}_{3} \mathrm{O}_{4}$ polydopamine nanoparticles as sorbent for magnetic dispersive solid-phase extraction of copper from food samples. Food Chem. 2018;263:232-9.

Zhang B, Du D, Meng M, Eremin SA, Rybakov VB, Zhao J, Yin Y, Xi R. Determination of amaranth in beverage by indirect competitive enzymelinked Immunosorbent assay (ELISA) based on anti-amaranth monoclonal antibody. Food Anal Methods. 2014;7(7):1498-505.

Zhang HY, Lyu SY, Zhou XM, Gu HB, Ma C, Wang CH, Ding T, Shao Q, Liu H, Guo ZH. Super light 3D hierarchical nanocellulose aerogel foam with superior oil adsorption. J Colloid Interface Sci. 2019a;536:245-51.

Zhang YD, An YF, Wu LY, Chen H, Li ZH, Dou H, Murugadoss V, Fan JC, Zhang $X G$, Mai XM, Guo ZH. Metal-free energy storage systems: combining batteries with capacitors based on a methylene blue functionalized graphene cathode. J Mater Chem A. 2019b;7(34):19668-75.

Zhao BQ, Shao Q, Hao LH, Zhang L, Liu Z, Zhang B, Ge SS, Guo ZH. Yeasttemplate synthesized Fe-doped cerium oxide hollow microspheres for visible photodegradation of acid orange 7. J Colloid Interface Sci. 2018;511:39-47.

\section{Publisher's Note}

Springer Nature remains neutral with regard to jurisdictional claims in published maps and institutional affiliations.

\section{Submit your manuscript to a SpringerOpen ${ }^{\circ}$ journal and benefit from:}

- Convenient online submission

- Rigorous peer review

- Open access: articles freely available online

High visibility within the field

- Retaining the copyright to your article

Submit your next manuscript at $>$ springeropen.com 